\title{
Research on Emotional Design of Ceramic Packaging
}

\author{
HuiHang ${ }^{1,} \mathrm{a}^{*}$, Junjian Liü, b Jianchun Shao ${ }^{3, c}$ \\ ${ }^{1}$ Jingdezhen Ceramic Institute, Jingdezhen , 333001,China \\ ${ }^{2}$ Jingdezhen Ceramic Vocational Technical College,Jingdezhen , 333001China \\ ${ }^{3}$ Jingdezhen Ceramic Vocational Technical College,Jingdezhen , 333001China \\ a114249216@qq.com, b48858523@qq.com, ${ }^{c j d z s j c @ 163 . c o m, ~}$
}

\begin{abstract}
Keywords: ceramic packaging, emotional, emotional design
Abstract. It analyzes research on emotional design of ceramic packaging. It is based on Donalod Norman's 《emotional design》, to analyze the positioning of ceramic packaging design. Through the analysis of the consumers' motive of self-consume, duty and selfish motives, it associated analyses three ceramic packaging design of the consume motivation, thus leads to the instinct level design strategy of the emotional design of ceramic packaging's shape, decoration, material, green packaging; the interactive behavior level design strategy of the convenient humanized design, the interactional peak experience; and the reflection level design strategy of the realization of self-image, the emotional reflection, the reflection of memory.
\end{abstract}

\section{Emotional Design}

Emotion is an attitude and experience held by people towards the subjective matters about whether such subjective matters will meet people's needs. It has played a significant role in practical life. Donald Norman, a famous industrial designer in USA has pointed out in his "Emotional Design" that: "Human brain activity can be classified into three levels: the visceral level, which is also the congenital part, the behavioral level that controls people's daily physical behaviors and the reflective level, where human brain works." The design at these three levels is implemented based on such a design philosophy that people have inner emotion and spiritual needs: the visceral level is such a level where people can perceive directly. It has been reflected through people's choice of shape, color and material etc. (it's also a level where visual sense, auditory sense and tactile sense within the range of physical characteristics dominate). The behavioral level, which is also the sensory level, can be reflected through human's emotional experience in the interaction with production function and performance. The reflective level, which is an in-depth experience, is embodied in the satisfaction with people's self image, the understanding and reflection on the wonderful feelings. In view of this, designs corresponding to these three levels are separately the visceral design, the behavioral design and the reflective design.

\section{Analysis on the Emotional Positioning of Ceramic Packages}

According to the applications, currently all of the ceramic products on the market can be classified into three major categories including domestic porcelain, artistic porcelain and industrial porcelain. More consumers can be found in the first two categories. However according to the survey and analysis on the consumers of the ceramic products, it reveals that the consumer's purchase motives mainly include the self-consuming motive, the compulsory-consuming motive and the egoistic consuming motive:

Self-consuming motive is mainly for an individual consumption with the purchase motive generally for the daily individual or household consumption to meet the requirements in daily life at home. Compulsory-consuming motive is a gifting motive with the main objects including friends, relatives and the elders for the exchange of gifts in daily life as the main consumption. Such a gifting motive is for mutual benefit, focusing on the symbolic meaning of the gift and the 
sentimental value. Egoistic consuming motive is also a gifting motive not for personal consumption. The parties involved in such a present-giving activity include the subordinates and superior in addition to the company and customers with the recipient always in a higher position. In this case, presents are given mainly for utilitarian purpose, based on which gifting activity is started to reconstruct the relationship or ascertain the emotional identity.

The analysis on the design style of the ceramic package based on the relevance of the consumption motives held by the consumers for the purchase of ceramic products has contributed to the intuitive understanding of the requirements on the design style of the ceramic package and the consumers' consumption motive. That's to say, different consumption motives correspond directly to different orientations for the design of ceramic package. According to the self-consuming motive, the emotional position for the ceramic package is: simple appearance and natural texture with the focus on the emotional expression of the warmth of life. Meanwhile the emotional position for the ceramic package based on the compulsory-consuming motive is: unique appearance to imply good fortune and happiness with the focus on the emotional expression of affinity. Based on the egoistic consuming motive, the emotional position for the ceramic package is: exquisite and elegant package with sophisticated process and exquisite materials filled with a sense of design to focus on the emotional expression of respect and decency.

\section{Strategy for the Emotional Design of Ceramic Packages}

According to the emotional design theory proposed by Donald Norman, it holds that the design of ceramic packages will stress the package protection function and the other functions that will facilitate the transportation, attract the consumers and promote the sales. Also from the perspective of visual design, it must emphasize the aesthetic and psychological functions that should be provided by the ceramic package, tending to the development of more amiable humane care. The emotional design of ceramic packages can be made successively at the following levels: the representation of the packages for the ceramic products (the visceral design), the intrinsic behavior embodied in the package of the ceramic products (the behavioral design) and the role played by the package of the ceramic products in the reflection of human thinking and feeling (the reflective design). Hence when emotional positioning of ceramic package is determined based on the consumers' different purchase motives, the emotional design can be made according to the design strategies at these three levels.

The Visceral Design Strategy for Ceramic Packages. The emotional design of ceramic packages on the instinctive level is the representation of the packages for the ceramic products, consisting of various responses shown in a series of perceptual experiences, which mainly refer to the interactions between human and objects according to the visual sense, the auditory sense, the sense of touch, the sense of taste and the sense of smell. Most of the emotions stimulated on the instinctive level are the primary emotions, which however are also the typical emotional responses that are the most direct and most severe with the strongest "visual impact" on the visceral level. Hence the emotional design of ceramic packages on the visceral level is always represented through the shape of the package, the decoration and the materials etc. to arouse people's "emotional resonance" under the intensive sensory stimulation including the diversified colors, the elegant appearance and the fashionable style.

Emotional Design on the Forms. In terms of the forms, generally carton, brocade box and wooden box in hexagonal structure are adopted in the ceramic packaging. The advantage is that such a structure will facilitate the protection of commodities in the transportation. But the deficiency is that it will lead to the visually aesthetic fatigue felt by the consumers, unable to arouse their emotional resonance. For example, if the package is made in the form of triangular prismor vertebrae, it will visually break away from convention with eye-catching appeal to arouse the consumers' attention and their desire to buy.

Emotional Design on the Decoration. Sensation methods that give the strongest visual impact, it's feasible to utilize abundant colors and fashionable styles to produce intensive visual stimulation. But at the same time, make sure to guarantee that the decorative style of the ceramic package 
conforms to the relevant ceramic product. For example, the adoption of the traditional decorative patterns (such as the blue-and-white, the clouding and the twine pattern etc.) on the traditional porcelain has played a significant role in the emphasis on the characteristics of the utensils. However for such chinaware with abstract decoration, it would be more suitable to adopt abstract geometric graphics and lines to represent it. As to such chinaware with colored glaze, it would be more proper to utilize the natural color of the materials that are made of wood, paper or brocade to give the plain and natural beauty of the colored glaze.

Emotional Design on the Materials On current ceramic market, the main materials of the package include paper (such as corrugated paper) and wood etc. Although it's true that all of such materials have their own advantages, it's still very hard to arouse the consumers' emotional resonance when they're used extensively. The adoption of linen as the material of the package is able to correspond effectively to the unglazed texture of the porcelain to deliver a plain, simple and elegant visual effect. The adoption of tinplate as the packing material not only lowers the cost, securing the package but also embodies a sense of fashion in the design.

The Behavioral Design Strategy for Ceramic Packages. The behavioral level refers to the intrinsic behavior of the ceramic packaging, focusing more on the product utility and the experience related to the utilization of the products. There're many aspects involved in such an experience, including the convenient user-friendly function, good performance and interactive experience etc., among which convenient function is the most important part in most of the behavioral designs. It's not a good design if the ceramic packaging design serves only for good-looking purpose, failing to provide convenient functions and excellent performance as required functionally. In view of this, the ceramic packaging design at behavioral level is actually a design serving for the interactive experience for special users in a specific usage environment for special purpose.

Convenient Humanized Design. The ceramic packaging design at behavioral level is human-oriented with the focus on the understanding and satisfaction of the consumer's demand. It's a necessity for the designer to understand and recognize those demands that haven't been met or even haven't been expressed. As soon as what the designer has recognized is applied in the design, good emotion will be created in the behavioral experience. For example, there's a wooden packing box for ceramic product. Instead of the application of the traditional metal button, the clasp of ivory or the bone prod, rope is adopted in the design to open or carry the package, which has broken away from convention. The reason is that on one hand, it's easy to open the box or tie a knot with a rope. On the other hand, it would be very convenient to carry the package with a rope. It's an emotional design embodied with humanistic care.

Interactive Experience. With the rapid development of modern information society, digital technology is able to provide more information platforms to the consumers through ceramic packaging so that they might have a better understanding of the ceramic products. For example, the scanning of the $\mathrm{QR}$ code on the ceramic package will provide an opportunity for people to understand the raw material of the product, the sintering temperature, the glaze material that has been applied and the mineral composition of the glaze material through information interaction. Such an interaction will facilitate the consumers to better understand the ceramic products they have purchased in a more active and more comprehensive way.

Moreover, the development of the information technology also provides the possibility to integrate the role of designer with the role of user. The access to the website information on the ceramic package will enable people to enter into the VR (virtual reality) show platform for the design of virtual ceramic products. There're abundant information and models related to product design in this platform system, where the consumers will be able to interact with the information on internet. Actually all of the consumers will be able to determine the appearance, the style, the decorative patterns, the color, the texture and the raw material of the product they will purchase according to their own preference on the VR technology platform via the internet, where all of the customized information will be sent to the manufacturer for production according to the orders.

The Reflective Design Strategy for Ceramic Packages. Emotion at reflective level is a higher-level emotion stimulation and experience. It's also the overall influence on the consumers as 
a result of the integration of the in-depth emotional experience, the cultural background, the ideology and the product impression under the effect of the previous two levels, bringing about a mentally pleasant and memorable emotion to people. The reflective design focuses on the product image, impression and the symbolic implication brought by the ceramic package so that the consumers might experience the relevant emotion after the understanding of the figurative meaning and the symbolic implication to simulate their deeper level of emotion to enjoy the pleasure brought by the packaging design. Generally the reflective design strategy is involved with the following three aspects:

Implementation of Self-image. When the consumers are purchasing the ceramic products, the articles they have purchased not only reflect their inner self-accomplishment, but also reflect their identity, status and values etc. At this moment, the ceramic products represent the consumer's image, able to make the user and the other person have the relevant emotional experience. As the external image of the ceramic product, the package must be able to show the corresponding image features of the product, namely the emotional elements for the consumers to reflect themselves. The package of the Shede liquor is indicated with special color, language and the graphic symbol, able to convey the character of Shede liquor and their pursuit for good taste, which is "The wisdom of life, the taste of Shede", revealing inadvertently the product and the taste of the owner.

Emotional Reflection. After the package of the ceramic products is endowed with symbolic significance, symbolic meaning or the metaphorical characteristics corresponding to the product, people will feel the great pleasure if they should read the meaning of the package and resonate with it when they're purchasing the product in such package. Since the shape of the package had been designed to satisfy the requirement of the utility function, then whether the performance can be expressed in the most efficient and direct way has been an important standard to measure the practicability of the package. However since human emotion is more than this, then the higher level of emotional demand will play a significant role in the packaging innovation for modern ceramic products.

Recall the Memory If the consumer feels "similar" when he is purchasing a certain ceramic product, the unconscious memory hidden in his mind thus can be dredged up. Such an emotional change from vague impression to clear thinking might make people feel cheerful and such a pleasure will last for a long time. Therefore regarding the design of the ceramic packages on the reflective level, it's applicable to design the package as a sensible presence that is familiar to people to bring a sense of belonging and security to the consumer.

\section{Conclusions}

The emotional design on the ceramic package is a precise positioning design to arouse the consumer's direct or indirect emotional experience in the ceramic product. Therefore in the design process, it would be very hard to arouse the consumer's resonance from the bottom of heart with a proper emotional design unless the consumer's hidden emotional demand would be mined to arouse the consumer's desire to purchase the ceramic product and have a profound emotion for the product. Actually regarding the design of the packages for the ceramic products, the memory and happiness brought to the consumers in the emotional process absolutely outweigh the usage value of the articles.

\section{References}

[1] Donalod Norman, "Emotional Design,"Publishing House of Electronics Industry , 2005 , p. $23-25$.

[2] Li Xiao-feng, Cheng Si , Wang Yu-nan and Wang Xiao-chun, "Emotional Design of Earthquake Emergency Relief Products,”.Packaging Engineering, Vol.32(2011)No. 14, p.44-47. 
[3] Xia Ya-qin,LI Wen-bo and Wu Xiang,"Emotional Design in Domestic Festival and Ceremonial Products, Packaging in Low-carbon Economy,"Packaging Engineering, Vol.31(2010) No. 16, p.162-164. 